\title{
Integrating Primary School Notification System with SMS Technology
}

\author{
Hawa Mohd Ekhsan ${ }^{1 *}$, Jiwa Noris Hamid ${ }^{2}$, Nurul Syakilah Mazlan ${ }^{3}$ \\ ${ }^{1,2,3}$ Faculty of Computer and Mathematical Sciences, Universiti Teknologi MARA Perlis Branch, \\ Malaysia \\ Corresponding author: *hawame@perlis.uitm.edu.my \\ Received Date: 1 September 2018 \\ Accepted Date: 4 October 2018
}

\begin{abstract}
This study presents the use of web SMS technology as an alternative method for primary school notification system. By integrating the system with SMS gateway, it will enable the primary school notification system to send information to parents' mobile phones directly. The traditional methods of notifying parents about the school matters by sending letters and written memos are time consuming and the updated information may not reach the parents. This integration allows information to be disseminated from computer to mobile phone at any time without requiring face-to-face meeting or the use of other media such as paper-based notice or verbal notice from the students. Furthermore, parents can always be alert and aware of the latest announcement or information no matter where they are. A usability testing was conducted on 20 users to survey the feedback on SMS technology to notify parents. The results from the testing stated that 100\% of the users gave positive feedback about the ease of use and were satisfied that the system can replace the old system. Based on the results, it shows that the integration of primary school notification system with SMS technology is highly recommended.
\end{abstract}

Keywords: primary school, notification system, SMS technology

\section{INTRODUCTION}

School notification plays an important role in disseminating information to parents at any time when there is an update regarding school activities, events or alerts to the students and parents. Traditionally, school notifications are delivered either by paper-based notice or verbal notice through the students. When schools inform the parents through letters of notification as the medium for delivering information, indirectly it would incur a relatively high cost in printing the letters.

On the other hand, if the notification is delivered verbally, some of the information is missing (Abdul Razak et al., 2016). Currently, some schools announce their notifications in the school website. Unfortunately, some of the parents are unable to access the school website since they have no Internet facilities. If schools continue with the current methods, important notifications cannot be sent to the parents effectively. These methods have some limitations that cause inaccurate information to be delivered to the targeted person and they are time-consuming as well (Abdul Razak et al., 2016). It may lead to dissatisfaction among parents due to the late and inaccurate notification and this may cause disturbance to their daily activities.

The need of a notification system is very crucial (Praswoto et al., 2017) especially for primary school students since they are still young and the ability to convey information is at the low level. Therefore, some of the important information are failed to be delivered to their parents (Kamaruddin et al., 2014). The notification system does not cost much, and parents can access the school's notification system at any time to find out the latest activities in school (Aftab et. al, 2013). 
In this digital age, mobile phone is widely used by parents and everyone expects the information to be delivered quickly and conveniently. Therefore, school administrative can take advantage of the use of mobile phone where parents can engage to school's activities or events. In order to ensure that information are delivered successfully to the parents, the use of Short Message Service (SMS) technology can be one of the opportunities. By using SMS technology, parents will get information faster (Olaleye et al., 2013; Akorede, 2017) and accurate since it provides better quality information and is reliable compared to the traditional ways.

This SMS technology can overcome the problem of availability of the Internet access among parents. This technology also encourages the society to support green technology with a paperless solution (Persada et al., 2014). The advantages of using SMS compared to other social media such as WhatsApp, Telegram, Twitter and other applications are SMS has a high 'open rate' and it is not dependent on Internet connection on the parents side especially in rural areas or for parents who cannot afford to have access to the Internet. Other than that, SMS notifications can be automated, and the history of old messages are stored in the inbox until the recipient deletes it. Furthermore, the SMS will be sent to the targeted recipient.

This research is aimed to develop a web-based school notification system for primary school and integrate it with SMS technology. The system is called ePSNS (electronic Primary School Notification System).

\section{HOW DOES EPSNS WORK?}

The web-based system will disseminate school notifications to the targeted recipients through SMS. The system will be administered by the school staff and it can be viewed by the parents. Parents can subscribe for SMS notification and the type of notification they need. The following subsections explain the important elements in ePSNS.

\section{SMS Broadcasting}

Executing a broadcast SMS is easier if all recipients' details have been stored in school database. With the SMS provider, such as Mobitek System Sdn. Bhd., the integration of SMS technology and the school notification system is easy.

Grouping recipients in the school notification system can make it easy and efficient to send the messages via SMS technology. In order to enable the school notification system to send messages from web browsers to mobile phones via SMS technology, SMS gateways must be integrated with the system.

\section{SMS Gateway}

SMS gateway is a service that allows SMS to be transmitted from other media to mobile phones such as from web browsers to mobiles. It deals with mobile service providers as well as to send messages to the recipients or subscribers. Hence, it sends SMS with sender identity as sender ID, and an authentication completes with security. This system was developed to improve the security level of SMS gateway. 


\section{Application Programming Interphase (API)}

An application programming interphase specifies how the components of software interact with each other. It describes the combination of all component of software from web-based to mobile phones. Figure 1 illustrates the services of Application Programming Interphase (API).

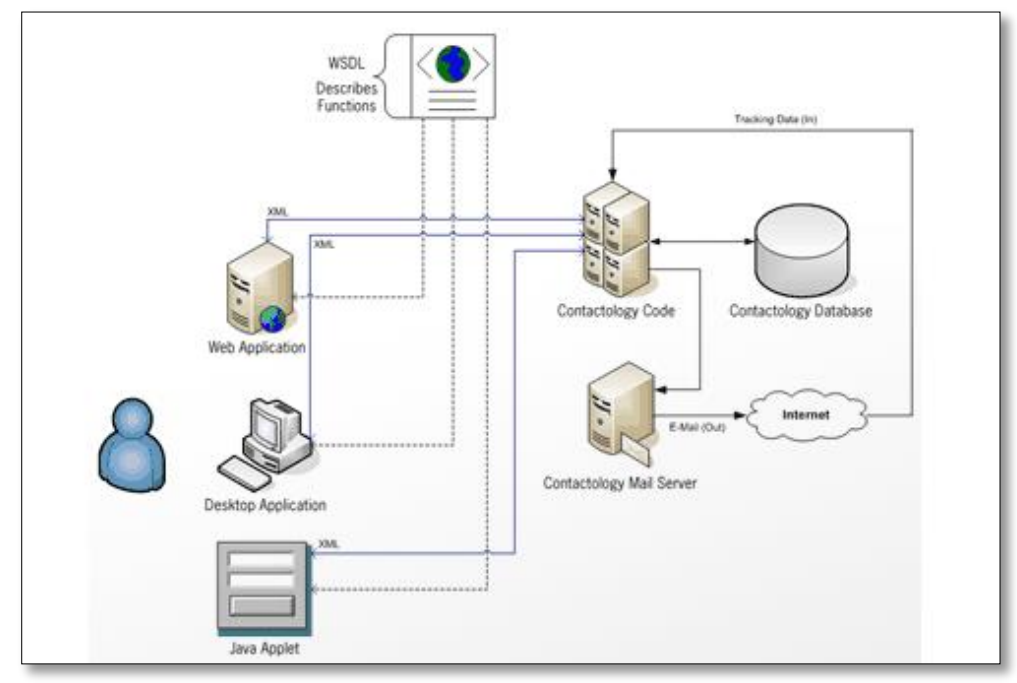

Figure 1: How Services of API Works

(Source from: Contactology website, 2013)

\section{Short Message Services Center}

The Short Message Services Center known as SMSC is responsible to ensure the message from the sender will be sent to the recipient. In addition, the SMSC is a middle bridge communicating sender and recipient. The exchanges of SMS always require SMSC to store and forward the messages and interact closely with mobile phones or the network (So, 2009).

Besides that, SMSC is highly reliable, with redundant backups for its primary functionality in case of failure. SMSC is able to serve a large number of subscribers, and thus can support a high throughput of messages.

\section{Types of Notification}

The notifications that involve in this research are school activities, meetings that involve parents, cancellation of extra classes or co-curricular activities and school off due to emergency issues.

\section{THE RESEARCH MODEL}

Figure 2 shows the research model that state the components of the proposed system. The Primary School Notification System is connected to MySQL database to retrieve parents' phone numbers. Then, it will be connected to SMS Gateway service that enables the system to send SMS to the targeted parents. 


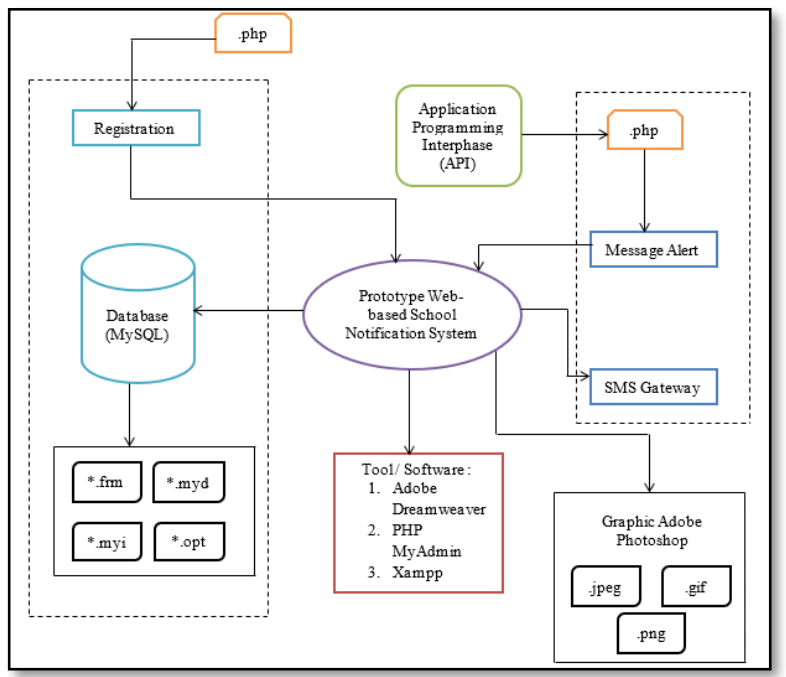

Figure 2: The Research Model of ePSNS

\section{THE PROTOTYPE}

The prototype has been developed using Adobe Dreamweaver with PHP language and MySQL database. Some of the system interfaces are shown in Figure 3.
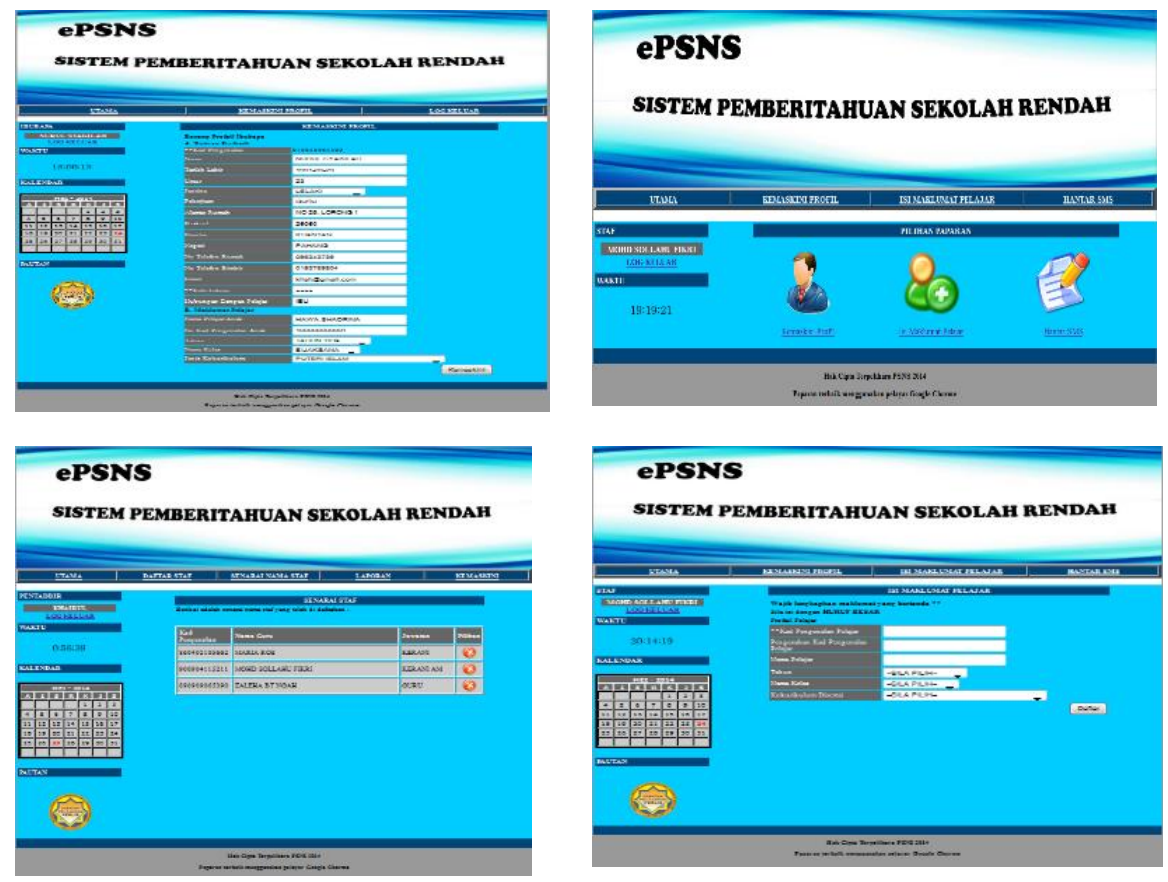

Figure 3: Interfaces of ePSNS

The SMS sending feature is shown in Figure 4. The SMS can be sent to individual or by group of recipients based on the class or extra co-curricular activities. 


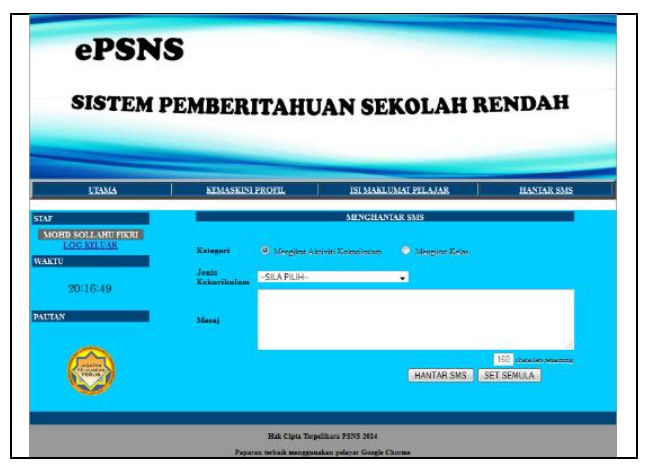

Figure 4: The 'Send SMS' Feature

\section{FINDINGS AND DISCUSSION}

The usability testing was done by the parents, staff and teachers at Sekolah Tengku Budriah, Arau, Perlis to gain the users' perception and their feedback. The feedback can be used to enhance and improve the system.

The testing has been conducted on 20 users including staff, teachers and parents. The users were given the tasks and a set of questionnaires was distributed to them after the system testing was completed. The usability testing results are shown in Table 1.

Table 1: Usability Testing Results

\begin{tabular}{|llcc|}
\hline No & \multicolumn{1}{c}{ Item } & Mean Score & Percentage \\
\hline $\mathbf{1}$ & I am satisfied with this system & 4.7 & $85 \%$ \\
\hline $\mathbf{3}$ & $\begin{array}{l}\text { The system is very easy to use and } \\
\text { simple }\end{array}$ & 5.0 & $100 \%$ \\
\hline $\mathbf{4}$ & $\begin{array}{l}\text { Using SMS in school notification system } \\
\text { is practical }\end{array}$ & 4.8 & $100 \%$ \\
\hline
\end{tabular}

The mean scores in Table 1 shows that most of the users are satisfied with the SMS notification system and they believe that the system can be used to replace the current practice at school.

\section{CONCLUSION AND RECOMMENDATION}

This school notification system is very significant since it can help the school to send information, activity or event notices via SMS technology that is faster and directly to the targeted recipient. Through this school notification system with SMS technology, thousands of parents will get the benefit since the notifications that they receive are accurate. It will also increase parental involvement by promoting events and programs in school.

The system can be improved by providing dual-language system which are the Malay language and English language. So, parents can choose which language they prefer thus the system is more convenient to use. The system can be upgraded where the administrator can check the SMS status either they are being delivered or not and the number of SMS remaining in the account. 


\section{REFERENCES}

Abdul Razak, S. F., Abdurahim, B., \& Mashhod, F. (2016). Keeping parents involved using 360-class Monitoring application. International Journal of Modern Education and Computer Science, 8(12), $10-16$.

Aftab, S., Khalid, A., Raza, A., \& Abbas, H. (2013). "Secure SMS Based Automatic Device Pairing Approach for Mobile Phones." 551-560

Akorede, M. F., Fatigun, J. J. \& Opaluwa, J. A. (2017). Efficient remote-control system using SMS and Wifi Technology for outdoor security lighting applications. IEEE PES PowerAfrica, Accra, 2017, 512-517.

Contactology website. (2013). "V1 - How Does It Work?". Retrieved December 01, 2013, 2013, from http://www.contactology.com/email-marketing-api/soap-api/how-does-it-work.php

Kamaruddin, A., Nagalingam, S. V. A.L., Admodisastro, N. \& Rasid, N. S. M. (2014). Parent personal information system to improve parental involvement in children's learning process in elementary school, 3rd International Conference on User Science and Engineering (i-USEr), 174-179.

Olayele, 0., Olaniyan, A., Eboda, 0., \& Awolere, A. (2013). SMS-based event notification system. Journal of Information Engineering and Applications, 3(10), 55 - 62.

Persada, S. F., Razif, M., Lin, S. C. \& Nadlifatin, R. (2014). Towards paperless public announcement on Environmental Impact Assessment (EIA) through SMS gateway in Indonesia. Proceedia Environmental Sciences, 20, $271-279$.

Prastowo, B. N., Dhewa, O. A., \& Putro, N. A. S. (2017). On the new-message notification of information systems. $2^{\text {nd }}$ International Conference on Science and Technology-Computer, $83-87$.

So, S. (October, 2009). The Development of a SMS-based Teaching and Learning System. Journal of Educational Technology Development and Exchange, Vol 2(1): 113-124. 